\title{
User Perception of Indoor Temperature and Preferences in Energy-Efficient Office Renovation Cases in the Netherlands
}

\author{
Minyoung Kwon ${ }^{1, *}$, Andy van den Dobbelsteen ${ }^{1}$, and Hilde Remøy ${ }^{2}$ \\ TU Delft, Faculty of Architecture and the Built Environment, \\ ${ }^{1}$ Department of Architectural Engineering + Technology, Julianalaan 134, 2628 BL Delft, The Netherlands \\ ${ }^{2}$ Department of Management in the Built Environment, Julianalaan 134, 2628 BL Delft, The Netherlands
}

\begin{abstract}
A comfortable indoor environment is one of the primary conditions of buildings. A majority of studies have attempted to compare occupant satisfaction of green-certificated offices and conventional offices. However, comparison of occupant perception with the adaptive comfort model may show differences and provide recommendations for the globe temperature in comfort. The purpose of this paper is to investigate the seasonal adaptation to indoor temperature, and to report the results of users' thermal perception surveys on energy efficient renovated office buildings. This work compares occupants' perception of indoor thermal quality. Data of indoor temperature were collected for 2 weeks in three seasons: summer, winter, and mid-season. Monitored indoor temperatures were compared with occupants' thermal sensation, preference, and satisfaction regarding thermal comfort. The research found the relationship between indoor temperature and occupants' thermal sensation. Results show that occupants perceived thermal quality better in renovated offices compared to non-renovated ones, but they do not always experience better thermal comfort than people in a non-renovated office.
\end{abstract}

\section{Introduction}

How people perceive the indoor environment in buildings is a growing area of research. User /occupant studies in the indoor environment show interactive relations [1], since uncomfortable work environments may lead to low productivity, and affect physical and mental health [2]. Thermal environmental quality is one of the most fundamental needs for building users [3]. Brager and Baker [4] stated occupants' satisfaction is highly influenced by thermal conditions. The occupants' comfort is often explored to assess the building condition after renovation. Still, a majority of building assessment research, dealing with building renovations, tend to focus on energy saving. Despite the benefits of energyefficient building renovation, buildings still have to achieve comfortable conditions for the work environment.

Many studies revealed that building energy can be saved by decreasing set-point temperature $[5,6]$, and by narrowing the range of temperature and humidity [7]. Theoretically, buildings controlled with a HVAC system should keep at least $80 \%$ of the users feeling comfortable [8]. However, when considering energy saving, thermal comfort is often compromised. It causes a substantial percentage of occupants feeling cold or hot [9]. According to Huizenga and Abbaszadeh [10], only 11\% of 215 office buildings had $80 \%$ of the occupants within the comfort range.
Therefore, it is interesting to see how the perception of occupants of renovated offices differs with those of non-renovated ones. In addition, it is also important to see how well-controlled thermal conditions are in energy-efficient renovated offices by comparing these with the outdoor temperature. Investigating users' thermal adaptation, perception and preferences can suggest solutions for a comfortable work environment that meets occupants' needs [11].

Current phenomenological studies in the built environment have focused on user experience by comparing past thermal experience and current thermal preferences of building users [1, 12], to give an insight into building users' expectations of the indoor climate. Thermal comfort analysis helps designers plan a proper environmental zone [4].

This paper presents the user perception of indoor temperature in renovated office buildings and nonrenovated ones based on a real-time field study. First, we discuss the occupant's thermal sensation of the indoor climate over a year's time, and subsequently their preference. Second, this study assesses the thermal satisfaction of users.

The result of this paper addresses the indoor thermal condition of energy-efficient offices, and provides a better understanding of the actual occupant perception in renovated offices. This study will be helpful in achieving user-focused thermal design of office buildings.

\footnotetext{
* Corresponding author: M.Kwon@tudelft.nl
} 


\section{Methods}

\subsection{Data collection}

\subsubsection{Monitoring indoor climate}

This paper presents four case studies of energy-efficient renovated offices (obtained energy label A or similar values) and one non-renovated one as a standard in the
Netherlands. Five offices were originally built during the 1960s and 1970s.and renovated within the last 10 years. Table 1 shows the information of case study offices.

Table 1. Description of case study buildings

\begin{tabular}{|c|c|c|c|c|c|}
\hline & Case A & Case B & Case C & Case D & Case E \\
\hline Description & $\begin{array}{l}\text { Location: Den } \\
\text { Haag, the } \\
\text { Netherlands } \\
\text { Built year: } 1973 \\
\text { Adaptation: } 2010 \text { - } \\
2011 \\
\text { Energy label } \\
\text { improvement: } \\
\text { F - A }\end{array}$ & $\begin{array}{l}\text { Location: } \\
\text { Amersfoort, } \\
\text { the Netherlands } \\
\text { Built year: } 1971 \\
\text { Adaptation: } 2012 \\
\text { Energy label } \\
\text { improvement: } \\
\text { G - A }\end{array}$ & $\begin{array}{l}\text { Location: Den Haag, the } \\
\text { Netherlands } \\
\text { Built year: } 1975 \\
\text { Adaptation: } 2008 \\
\text { Energy label } \\
\text { improvement: Energy } \\
\text { label A, BREEAM *** }\end{array}$ & $\begin{array}{l}\text { Location: Den } \\
\text { Haag, the } \\
\text { Netherlands } \\
\text { Built year: } 1960 \text { s } \\
\text { Adaptation: } 2012 \\
\text { Energy label } \\
\text { improvement: } \\
\text { BREEAM } \\
\text { Excellent }\end{array}$ & $\begin{array}{l}\text { Location: Delft, the } \\
\text { Netherlands } \\
\text { Built year: } 1960\end{array}$ \\
\hline
\end{tabular}

The data were collected by monitoring the actual indoor climate for two weeks during each season: July, October in 2017, and January in 2018. HOBO loggers were placed $1.1 \mathrm{~m}$ above floor level in different orientations of workplaces, in the middle of the room, avoiding unexpected heat such as direct sunlight and heat from computers or monitors. The indoor climate data measured include temperature, relative humidity, and illuminance. Outdoor temperature was obtained from the nearest meteorological station.

\subsubsection{User perception survey}

Online-based thermal comfort surveys were conducted in five offices. The survey included three questions as follows:

Q1. How do you experience the indoor temperature of your workspace? (for mid-season, summer and winter)

Q2. How would you prefer the indoor temperature to be?

Q3. How satisfied are you with the thermal conditions?

7-point and 3-point scale methods were adopted to determine the occupants' thermal sensation and preference questions. Each option of these questions was allocated a score, as shown in Table 1. The scales of thermal sensation vote (TSV) and thermal preference (TP) were based on ASHRAE Standard-55 [13] and on the Mclntyre scale [14] respectively. For the satisfaction survey, respondents were asked to rate their satisfaction on a five-point Likert scale: 1 = extremely dissatisfied, 2 $=$ somewhat satisfied, $3=$ neither dissatisfied nor satisfied, $4=$ somewhat satisfied, and $5=$ extremely dissatisfied.
Table 2. Questionnaires used in thermal perception and preference surveys

\begin{tabular}{ccc}
\hline Number & $\begin{array}{c}\text { Thermal sensation } \\
\text { vote (TSV) }\end{array}$ & $\begin{array}{c}\text { Thermal preference } \\
\text { (TP) }\end{array}$ \\
\hline 1 & Cold & Cooler \\
2 & Cool & No change \\
3 & Slightly cool & Warmer \\
4 & Neutral & \\
5 & Slightly warm & \\
6 & Warm & \\
7 & Hot & \\
\hline
\end{tabular}

\subsection{Data analysis}

\subsubsection{Thermal perception and preference}

The analysis of occupant responses was conducted by statistical software programme SPSS 24 (Statistical Packages for the Social Sciences). With calculations of the mean value, frequency distribution was included. Additionally, an ANOVA test was used to test differences between mean values (office cases and thermal perception) with the significant level of 0.05 .

\subsubsection{Indoor thermal condition and adaptive comfort}

The calculation of the internal thermal comfort range was based on the ISSO 74 of 2014 for Beta spaces [15]. Beta space can be applied for centrally controlled spaces [16]. The adaptive comfort model has four categories according to a level of expectation of thermal comfort. Category A, B, C, and D for the upper and lower limit of comfort was obtained by using the following equations.

$\theta_{\mathrm{rm}}$ is the running mean outdoor temperature for the temperature of the experiment day, and for these

\footnotetext{
Corresponding author: M.Kwon@tudelft.nl
} 
equations $10^{\circ} \mathrm{C} \leq \mathrm{T}_{\text {out }} \leq 16^{\circ} \mathrm{C}$ was applied for the upper limit, and $10^{\circ} \mathrm{C} \leq \mathrm{T}_{\text {out }}<25^{\circ} \mathrm{C}$ for the lower limit.

Upper limit of class $\mathrm{D}=0.33 * \mathrm{~T}_{\text {out }}+22.8$

Lower limit of class $\mathrm{D}=0.2 * \mathrm{~T}_{\text {out }}+16$

Upper limit of class $\mathrm{C}=0.33 * \mathrm{~T}_{\text {out }}+21.8$
Lower limit of class $\mathrm{C}=0.2 * \mathrm{~T}_{\text {out }}+17$

Upper limit of class B $(A)=0.33 * \mathrm{~T}_{\text {out }}+20.8$

Lower limit of class $B(A)=0.2 * T_{\text {out }}+18$

The temperature zone of $-5{ }^{\circ} \mathrm{C} \leq \mathrm{T}_{\text {out }}<10^{\circ} \mathrm{C}$ and $16^{\circ} \mathrm{C}$ $<\mathrm{T}_{\text {out }} \leq 25^{\circ} \mathrm{C}$ follows the instruction in Table 2 .

Table 3. Instruction for different temperature zone (ISSO 74: 2014)

\begin{tabular}{|l|c|c|c|}
\hline \multirow{2}{*}{ Class } & \multicolumn{2}{|c|}{ Upper limit } & Lower limit \\
\cline { 2 - 4 } & $-5^{\circ} \mathrm{C} \leq \mathrm{T}_{\text {out }}<10^{\circ} \mathrm{C}$ & $16^{\circ} \mathrm{C}<\mathrm{T}_{\text {out }} \leq 25^{\circ} \mathrm{C}$ & $-5^{\circ} \mathrm{C} \leq \mathrm{T}_{\text {out }}<10^{\circ} \mathrm{C}$ \\
\hline $\mathrm{D}$ & 26 & 28 & 18 \\
\hline $\mathrm{C}$ & 25 & 27 & 19 \\
\hline $\mathrm{B}, \mathrm{A}$ & 24 & 26 & 20 \\
\hline
\end{tabular}

\section{Results}

\subsection{Indoor temperature}

Table 4 compares the indoor temperature of different orientations in the 5 case studies. The measured temperature was considered for working hours from 7.00 am to $9.00 \mathrm{pm}$. NEN 15251 guideline recommends maintaining the indoor temperature between $23-26^{\circ} \mathrm{C}$ as comfort zone in summer, and between $20-24{ }^{\circ} \mathrm{C}$ in winter.

Overall, the non-renovated office had reached the extreme indoor temperature minimum of under $14.4^{\circ} \mathrm{C}$ during winter, and maximum of $34.4^{\circ} \mathrm{C}$ during summer. During winter, the office energy-labelled A also reached a temperature under $20^{\circ} \mathrm{C}$. However, this tendency was observed on Monday since HVAC systems do not run during weekend.

Figure 4 shows the range of adaptive thermal comfort. According to ISSO 74:2014, category A indicates a high level of expectation of thermal comfort that demand a higher comfort level (sensitive people or persons who have diseases). Category $\mathrm{B}$ is for a normal level of expectation. This category is for new buildings or in the case of substantial renovations. Class $\mathrm{C}$ is for a moderate level of expectation, selected in the case of old existing buildings. Class D is for a limited level of expectation, applied to temporary buildings or limited use.

Overall, most of case offices were not 100 percent qualified for adaptive comfort zone A and B. Instead, the temperature points were often distributed in lower temperature zones than the adaptive comfort zone. Case $\mathrm{C}$ was often out of comfort zone with a low temperature. Case D showed the smallest temperature differences between 20 and $26^{\circ} \mathrm{C}$. On the other hand, Case $\mathrm{E}$ building was often above $28^{\circ} \mathrm{C}$. When the outdoor temperature was below $16^{\circ} \mathrm{C}$, it was out of category $\mathrm{A}$ or $\mathrm{B}$ zone, but still stayed within category $\mathrm{C}$ (for old existing buildings). The range of indoor temperature in energy renovated offices were generally lower than that of a comfort zone.

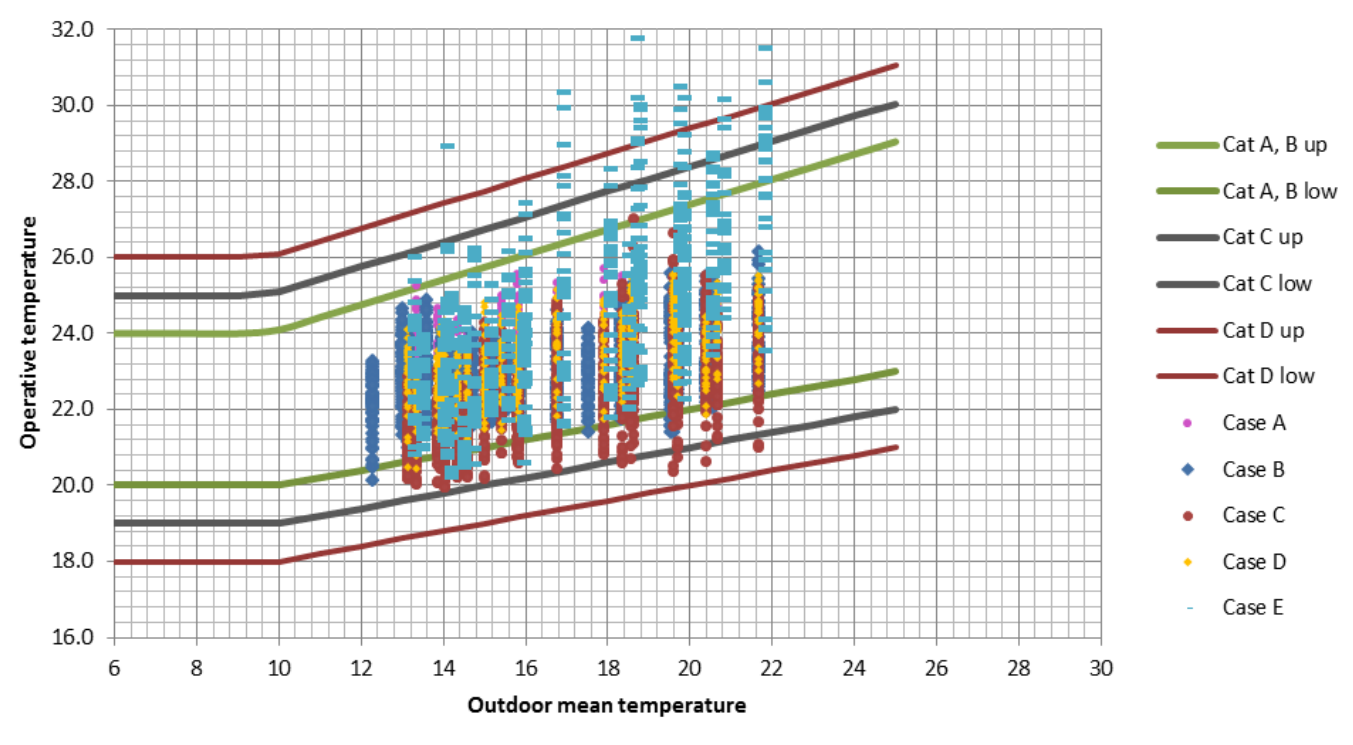

Fig. 1. Adaptive thermal comfort model in the Dutch ISSO 74:2014.

\footnotetext{
* Corresponding author: M.Kwon@tudelft.nl
} 
Table 4. Monitored data of indoor temperature in October, July and January

\begin{tabular}{|c|c|c|c|c|c|c|c|c|c|c|c|c|c|c|c|}
\hline \multirow{2}{*}{\multicolumn{2}{|c|}{ Temperature }} & \multicolumn{2}{|c|}{ Case A } & \multicolumn{4}{|c|}{ Case B } & \multicolumn{4}{|c|}{ Case C } & \multicolumn{2}{|c|}{ Case D } & \multicolumn{2}{|c|}{ Case E } \\
\hline & & S.E & N.W & S.W & S.E & N.E & N.W & S.W & S.E & N.E & N.W & S.W & N.E & S.W & N.E \\
\hline \multirow{3}{*}{$\begin{array}{l}\text { Mid- } \\
\text { season }\end{array}$} & Max. & 25.7 & 23.7 & 24.9 & 24.3 & 23.1 & 24.1 & 24.3 & 24.3 & 23.9 & & 24.9 & 24.8 & 28.9 & 26.7 \\
\hline & Min. & 21.3 & 20.9 & 20.7 & 20.7 & 20.5 & 20.1 & 20.2 & 20.0 & 20.1 & & 22.2 & 20.4 & 20.2 & 20.8 \\
\hline & $\begin{array}{l}\text { Mean } \\
\text { value }\end{array}$ & 23.4 & 22.2 & 23.1 & 23.1 & 22.4 & 22.6 & 21.8 & 22.0 & 21.5 & & 23.2 & 22.6 & 22.8 & 23.7 \\
\hline \multirow{3}{*}{ Summer } & Max. & 25.5 & 24.8 & 24.8 & 25.5 & 24.8 & 26.2 & 26.6 & 24.0 & 25.5 & 30.0 & 25.4 & 25.6 & 32.1 & 34.4 \\
\hline & Min. & 22.8 & 22.1 & 21.4 & 21.9 & 22.1 & 21.7 & 22.1 & 20.3 & 20.9 & 21.2 & 22.3 & 21.8 & 21.3 & 22.0 \\
\hline & $\begin{array}{l}\text { Mean } \\
\text { value }\end{array}$ & 24.2 & 23.1 & 22.5 & 24.0 & 23.0 & 23.9 & 23.4 & 22.0 & 23.1 & 23.7 & 23.8 & 24.1 & 24.8 & 26.7 \\
\hline \multirow{3}{*}{ Winter } & Max. & 27.0 & 22.1 & 22.9 & 23.8 & 22.9 & 22.8 & 23.3 & 25.0 & 25.4 & 23.8 & 22.4 & 24.9 & 24.03 & 23.21 \\
\hline & Min. & 18.0 & 18.1 & 19.4 & 20.1 & 19.5 & 18.9 & 19.5 & 19.7 & 20.5 & 19.9 & 20.46 & 21.8 & 17.13 & 14.41 \\
\hline & $\begin{array}{l}\text { Mean } \\
\text { value }\end{array}$ & 24.3 & 22.1 & 21.6 & 22.6 & 22.0 & 21.6 & 21.2 & 21.5 & 22.8 & 21.6 & 22.4 & 22.8 & 21.3 & 20.0 \\
\hline
\end{tabular}

\subsection{Distribution of thermal perception}

The data were collected in the year 2017 and 2018. The total number of responses were $606(95.1 \%)$ out of a total of 637 approached office users. The group of respondents comprised $308(50.8 \%)$ of males and 298 $(49.2 \%)$ of females.

In Table 2, the mean TSV of case A, B, and C was similar over a season. However, the lowest mean value was shown in case $\mathrm{D}$, which means most people felt relatively cool or cold compared to other offices, despite the renovated office. In reverse, occupants in case E (the non-renovated case) felt warmer or hotter in mid-season and summer than those in other offices. In terms of seasonal comparison, mid-season and winter showed similar mean TSV values.

Table 5. Mean value of thermal sensation vote in different seasons

\begin{tabular}{llllll}
\hline Mean & Case A & Case B & Case C & Case D & Case E \\
\hline Mid-season & 3.87 & 3.81 & 3.88 & 2.68 & 4.27 \\
Summer & 4.18 & 4.04 & 4.24 & 3.59 & 6.08 \\
Winter & 3.87 & 3.38 & 3.46 & 2.56 & 3.48 \\
\hline
\end{tabular}

Fig 1, 2, and 3 show the subjective responses to thermal sensation in different seasons. A thermal comfort zone was considered the vote scale of 3 to 5 . At least $80 \%$ of occupants should vote the range of 3 to 5 for an acceptable thermal environment [13]. In midseason, TSV did not differ between case A, B and C. Around $80 \%$ of building occupants voted slightly cold, neutral, and slightly warm, whereas only $20 \%$ occupants felt comfortable in case D.

People, in general, felt warm in summer (see Fig. 2). Case A, B, and C could reach 60 to $70 \%$ of thermal comfort, while only $20 \%$ of people felt comfortable in case D and E. Interestingly, $46 \%$ of the occupants in case $\mathrm{D}$ voted cold or cool, and $76 \%$ occupants voted warm and hot in case $\mathrm{E}$.
In winter, renovated and non-renovated offices reached $65 \%-75 \%$ of occupant comfort (see Fig. 3). Only case D showed a low percentage of occupant comfort: only $20 \%$. $66 \%$ of the building users felt cool or cold with the indoor temperature.

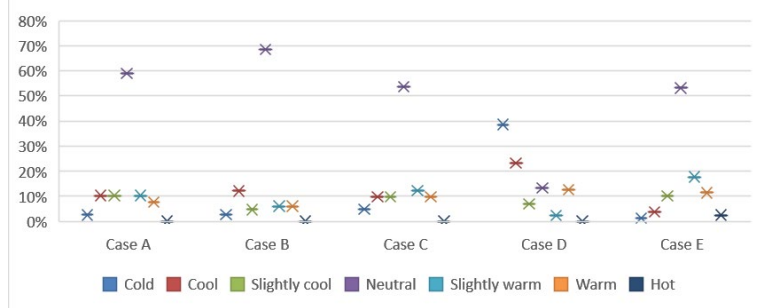

Fig. 2. Distribution of occupants' thermal perception in midseason.

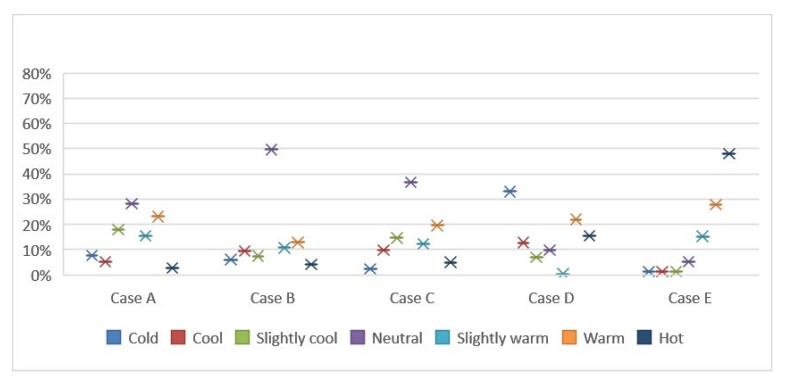

Fig. 3. Distribution of occupants' thermal perception in summer.

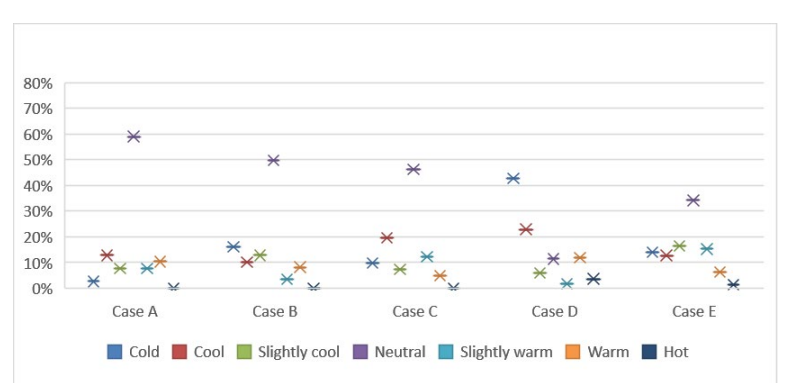

Fig. 4. Distribution of occupants' thermal perception in winter.

\footnotetext{
* Corresponding author: M.Kwon@tudelft.nl
} 


\subsection{User preference of indoor temperature}

Figure 4-6 show the occupants' thermal preference in different seasons compared to the current indoor temperature. Thermal preference votes differed significantly across the periods. A majority of people in case B and E responded 'no change' with indoor temperatures in mid-season (see Fig. 4). 57\% of the occupants in case $\mathrm{D}$ expected warmer thermal conditions than the actual temperature. During summer, the percentage of people who responded 'no change' decreased in the five cases. Case E showed the most significant drop of the answer of 'no change'. It is assumed that case $\mathrm{E}$ does not provide air conditioning or mechanical ventilation, however natural ventilation. Around 35 to $40 \%$ expected cooler indoor temperatures in summer (see Fig. 5). Although the percentage of people who voted 'no change' with indoor temperature in winter, around $60 \%$ of the occupants from each office answered 'no need to change the temperature'. However, $30 \%$ of all occupants preferred the thermal environment to be warmer. It is worth to mention that people in Case $\mathrm{D}$ rarely felt a proper indoor temperature. They preferred warmer temperatures during mid-season and winter. In summer $37 \%$ and $41 \%$ of the occupants still expected the temperature to be warmer or cooler respectively.

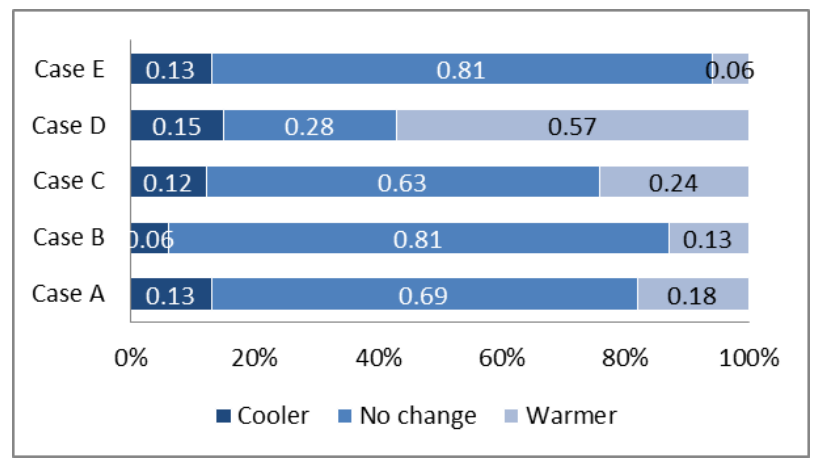

Fig. 5. Occupants' thermal preference in mid-season, compared to current temperature.

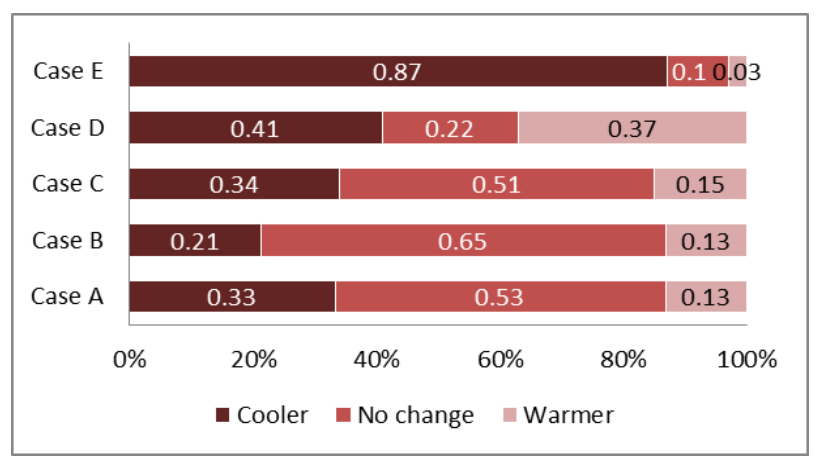

Fig. 6. Occupants' thermal preference in summer, compared to current temperature.

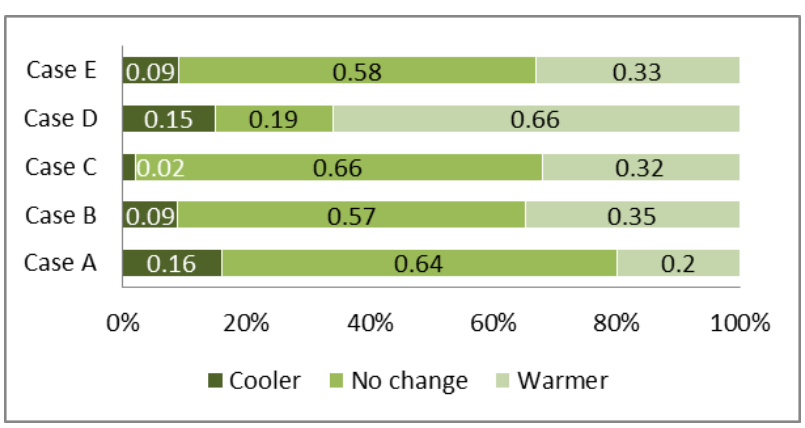

Fig. 7. Occupants' thermal preference in winter, compared to current temperature.

\subsection{User satisfaction of indoor temperature}

Occupants were generally satisfied with the indoor temperature across the periods with approximately 3.5 of mean value. Case D had a substantially low mean value over all seasons, but the mean value of other renovated offices was, in general, slightly higher than for the nonrenovated office. Although the adaptive comfort of case $B$ was not the ideal model, the responses of the occupants' perception, preference, and satisfaction were the best.

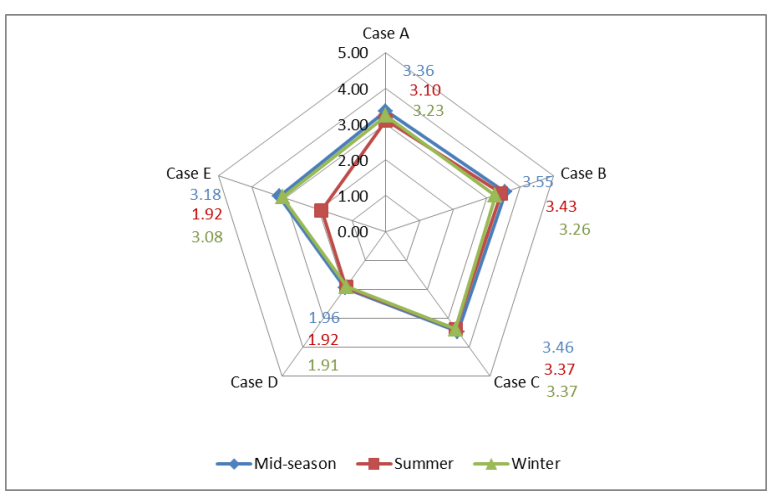

Fig. 8. Mean value of occupant's satisfaction vote

Overall, the case of a non-renovated office had an uncomfortable temperature issue only in summer. An energy renovated office building that is performing exceptionally well, based on global comfort standards, showed least user satisfaction with thermal comfort. A high percentage of occupants who were unsatisfied was observed in an office that achieved great adaptive thermal comfort.

\section{Discussion}

The limitation of this study is the adaptive approach to thermal comfort. Some critical issues have stated that the current global standards for adaptive comfort mainly focus on naturally ventilated buildings. The case studies selected in this study are mixed-mode buildings, neither air-conditioned nor fully naturally ventilated. Therefore, ISSO 74 was applied to analyse the adaptive comfort. This Beta model can be applied for conditioned spaces. However, the new version of ISSO 74 was developed

\footnotetext{
* Corresponding author: M.Kwon@tudelft.nl
} 
with SCATs European comfort field study database [16]. It is not a global standard but forms the basis for Dutch building regulation.

\section{Conclusion}

For a year, thermal perception surveys were held with occupants in energy-efficient renovated offices in the Netherlands. The following results were found:

- When people prefered not to change the temperature, they were satisfied with the thermal comfort. However, this 'neural' of thermal sensation did not mean people were highly satisfied with thermal comfort.

- The ideal temperature for occupant comfort was observed $22.5-23.1^{\circ} \mathrm{C}$ or $23.8-24.0^{\circ} \mathrm{C}$ in summer, and 21.6 and $22^{\circ} \mathrm{C}$ in winter, and $22.4-23.1^{\circ} \mathrm{C}$ in mid-season.

- In winter, occupants were dissatisfied with the indoor temperature of over $22.8^{\circ} \mathrm{C}$.

- Occupants easily adapted cooler temepratures than warmer ones.

- The occupants were less comfort with highly achieved great adptive thermal comfort. Therefore, the range of adaptive thermal comfort needs to be considered.

From this comparision study, it was difficult to find the comfortable temperature range since the thermal satisfaction of occupants showed different results than the adaptive thermal comfort model. Even though the indoor temeperature was within the comfort zone, people were dissatisfied with the temperature. It can be assumed that there may be other factors that affect the occupants' thermal satisfaction.

This project is supported by Delft University of Technology and the company SangLimWon CO., Ltd. It is a landscape architecture/construction company in South Korea. This research is a part of scientific and technical activities in the company. The paper was made possible with support from architects and facility/asset managers of the office buildings analysed: KCAP in Rotterdam, MVSA in Amsterdam, Fokkema \& Partners Architecten in Delft, Royal HaskoningDHV in Amersfoort, DGMR, CAK, and The Ministry of Finance in Den haag, all in the Netherlands. We also thank all employees who participated in the online survey for data collection.

\section{References}

1. J.C.Vischer, , Towards a user-centred theory of the built environment. Building Research \& Information, 36(3): p. 231-240 (2008).

2. Sant'Anna, D.O., et al., Indoor environmental quality perception and users' satisfaction of conventional and green buildings in Brazil. Sustainable Cities and Society, 43: p. 95-110 (2018)
3. R. Mora, and R. Bean, Thermal Comfort: Designing for People. ASHRAE J, 60: p. 40-46 (2018)

4. G. Brager, and L. Baker, Occupant satisfaction in mixed-mode buildings. Building Research \& Information, 37(4): p. 369-380 (2009)

5. T. Hoyt, E. Arens, and H. Zhang, Extending air temperature setpoints: Simulated energy savings and design considerations for new and retrofit buildings. Building and Environment, 88: p. 89-96 (2015)

6. J. Verhaart, , M. Veselý, and W. Zeiler, Personal heating: effectiveness and energy use. Building Research \& Information, 43(3): p. 346-354 (2015)

7. M. Luo, E. Arents, H. Zhang, A. Ghahramani, and Z. Wang, Thermal comfort evaluated for combinations of energy-efficient personal heating and cooling devices. Building and Environment, 143: p. 206-216 (2018)

8. A.C. Cosma, and R. Simha, Thermal comfort modeling in transient conditions using real-time local body temperature extraction with a thermographic camera. Building and Environment, 143: p. 36-47 (2018)

9. E. Arens, M.A. Humphreys, R. de Dear, H. Zhang Are 'class A'temperature requirements realistic or desirable? Building and Environment, 45(1): p. 4$10(2010)$

10. C. Huizenga, S. Abbaszadeh, L. Zagreus, and E. Arens, Air quality and thermal comfort in office buildings: results of a large indoor environmental quality survey. Proceeding of Healthy Buildings, 3, 393-397 (2006)

11. H.B. Rijal, M.A. Humphreys, and J.F. Nicol, Towards an adaptive model for thermal comfort in Japanese offices. Building Research \& Information, 45(7): p. 717-729 (2017)

12. R. De Dear, and G.S. Brager, Developing an adaptive model of thermal comfort and preference. UC Berkeley: Center for the Built Environment, (1998)

13. ASHRAE Standard 55-2013. Thermal environmental conditions for human occupancy, $\mathrm{p}$. 12, (2013)

14. K. Cena, and J.A. Clark, Bioengineering, Thermal Physiology and Comfort, Elsevier Science (1981)

15. A. Boerstra, J. Van Hoof, and A. Van Weele, A new hybrid thermal comfort guideline for the Netherlands: background and development. Architectural Science Review, 58(1): p. 24-34 (2015)

16. S. Carlucci, L. Bai, R. de Dear, L. Yang, Review of adaptive thermal comfort models in built environmental regulatory documents. Building and Environment, 137: p. 73-89 (2018)

\footnotetext{
* Corresponding author: M.Kwon@tudelft.nl
} 